\title{
Viscoelastic Properties of Concentrated Solutions of Mixtures of Three- and Four-Branched Star Polystyrenes*
}

\author{
Yasuhiko OHTA, Mitsunobu KitAmura, Toshiro MASUdA, \\ and Shigeharu ONOGI \\ Department of Polymer Chemistry, Kyoto University, \\ Sakyo-ku, Kyoto 606, Japan.
}

(Received December 24, 1980)

\begin{abstract}
Viscoelastic properties of concentrated solutions of mixtures of three- and fourbranched polystyrenes were measured by a concentric cyclinder type rheometer and compared with those of undiluted star-shaped polymers having the same type of branching and linear polystyrenes studied previously. The viscoelastic parameters, zero-shear viscosity $\eta_{0}$, steady-state compliance $J_{\mathrm{e}}{ }^{0}$, and entanglement compliance $J_{\mathrm{eN}}^{0}$, have been evaluated from the frequency dependences of storage shear modulus $G^{\prime}(\omega)$ and loss modulus $G^{\prime \prime}(\omega) . \eta_{0}$ for 50 and $90 \mathrm{wt} \%$ solutions are proportional to $M_{w}^{4.5}$ at high molecular weight. $J_{\mathrm{e}}{ }^{0}$ for $90 \mathrm{wt} \%$ solution is independent of molecular weight, while $J_{\mathrm{e}}{ }^{0}$ for $50 \mathrm{wt} \%$ solution depends on molecular weight. The unusual behavior found is that the $J_{\mathrm{e}}{ }^{0}$ value for $50 \mathrm{wt} \%$ solution of star polystyrenes is lower than those for a $90 \mathrm{wt} \%$ solution and an undiluted polymer at the same molecular weight.
\end{abstract}

KEY WORDS Viscoelasticity / Polystyrene / Branched Polymer / Viscosity / Steady-State Compliance / Entanglement Compliance / Molecular Weight Dependence /

A lot of investigations ${ }^{1-28}$ concerning the effect of branching on rheological properties of polymer liquids have been made during the past more than two decades. These studies clearly demonstrate that the rubbery and flow properties of viscoelastic liquids are affected by branching. During the 1970's, the viscoelastic properties of branched polymers well characterized with respect to both the type of branching and the number and length of branches have been reported..$^{9-23}$

The forerunning experimental studies on viscoelasticity of well characterized branched polymers were published in 1970 and 1971 for comb-shaped ${ }^{11}$ and star-shaped polystyrenes. ${ }^{16}$ These measurements revealed an interesting feature of the elasticity of branched polymers that the steady-state compliance $J_{\mathrm{e}}^{0}$ is independent of molecular weight and is about ten times as high as that of linear polymers.

On the other hand, very recent experimental

\footnotetext{
* Rheological Properties of Anionic Polystyrenes. IX.
}

results ${ }^{20,22}$ on star-shaped polystyrenes show that the $J_{\mathrm{e}}{ }^{0}$ of branched polymers are lower than those for linear ones when the concentration $(c)$ and/or molecular weight $(M)$ are sufficiently low. With increasing molecular weight, $J_{\mathrm{e}}{ }^{0}$ keeps increasing in proportion to $M$, and the relation between $J_{\mathrm{e}}{ }^{0}$ and $M$ can be approximately represented by the RouseHam theory. ${ }^{24,25}$ This behavior of $J_{\mathrm{e}}{ }^{0}$, which seems to be well established now, is quite different from that formerly reported on comb- ${ }^{11}$ and star-shaped polystyrenes. ${ }^{16}$

As pointed out in our 1971 paper, ${ }^{16}$ the star samples investigated were mixtures of three- and four-branched polystyrenes, and this fact was also suggested by an experimental study on dilute solutions of the same samples. ${ }^{29}$ The comb-shaped polystyrenes used by Fujimoto et al. ${ }^{11,12}$ essentially have a statistical distribution in the number of branches when judged by the synthetic method they used. The difference in the behavior of $J_{\mathrm{e}}{ }^{0}$ mentioned above might be attributed to the distribution of the number of branches and the molecular 
Table I. Weight- and number-average molecular weights, their ratios, molecular weights of one branch $M_{\mathrm{s}}$ and average numbers of branches for star and linear polystyrenes

\begin{tabular}{|c|c|c|c|c|c|c|}
\hline & & $M_{w} \times 10^{-5}$ & $M_{n} \times 10^{-5}$ & & $M_{\mathrm{s}} \times 10^{-5}$ & \\
\hline & & ls & os & & os & \\
\hline \multirow{4}{*}{ Star } & LB26 & 5.95 & 5.07 & 1.17 & 1.46 & 3.47 \\
\hline & LB27 & 3.80 & 3.18 & 1.20 & 0.811 & 3.92 \\
\hline & LB28 & 2.00 & 1.76 & 1.14 & 0.502 & 3.51 \\
\hline & LB29 & 1.13 & $0.85^{8}$ & 1.32 & 0.257 & 3.34 \\
\hline \multirow{3}{*}{ Linear } & PS613 & 13.0 & 10.0 & 1.30 & - & 2 \\
\hline & PS711 & 4.35 & 3.64 & 1.20 & - & 2 \\
\hline & PS712 & 2.05 & 1.32 & 1.13 & - & 2 \\
\hline
\end{tabular}

weight distribution.

In the present paper, rheological properties are reported for concentrated solutions of mixtures of star-shaped polystyrenes with three- and fourbranches. The molecular weight dependences of viscoelastic parameters, such as viscosity and steady-state compliance, were determined at various concentrations, and the effect of the distribution in the number of branches was investigated by comparing the experimental results with those for linear polystyrenes, ${ }^{9}$ for undiluted samples with the same type of branches, ${ }^{16}$ and for bimodal blends of linear polystyrenes. ${ }^{30,31}$

\section{EXPERIMENTAL}

\section{Materials}

The star polystyrenes of different molecular weights used in this study were prepared by coupling polystyryl anions with silicon tetrachloride as reported previously. ${ }^{16}$ The fractionation of each whole polymer was repeated three times with a benzene-methanol mixture to separate the starbranched polymers. The weight- $\left(M_{w}\right)$ and numberaverage $\left(M_{n}\right)$ molecular weights, their ratios and the average number of branches $(P)$ for the samples employed are given in Table I. The LB- and PSseries in this table correspond to the branched and linear polystyrenes, respectively. $M_{n}$ and $M_{w}$ were determined by osmotic pressure and light scattering methods. The efficiency of the three-stage fractionation was checked by gel permeation chromatography (Waters Model 200) in tetrahydrofuran at $40^{\circ} \mathrm{C}$ and by analytical ultracentrifugation (MOM Model 3170 ) of $0.35 \%$ solutions in cyclo-

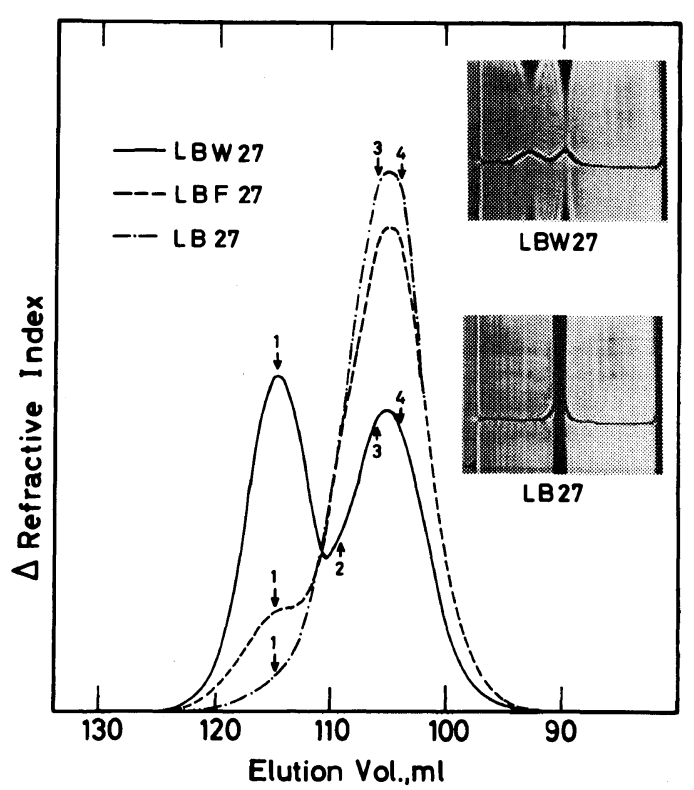

Figure 1. The gel permeation chromatograms (GPC) and the sedimentation patterns for LBW27 (unfractionated), LBF27 (after the first-stage fractionation) and LB27 (after the three-stage fractionation). The GPC were measured by a Waters Model 200 in tetrahydrofuran at $40^{\circ} \mathrm{C}$, and the sedimentation patterns were taken by a MOM Model 3170 for $0.35 \%$ cyclohexane solutions at $50,000 \mathrm{rpm}, 35^{\circ} \mathrm{C}$ and $75 \mathrm{~min}$.

hexane at $35^{\circ} \mathrm{C}$. As examples, the gel permeation chromatograms (GPC) and the sedimentation patterns at 50,000 rpm for an unfractionated sample LBW27 and a final fraction LB27 are shown in Figure 1, where LBF27 denotes the sample obtained after the first fractionation of LBW27. The arrow with a number in this figure indicates the 
elution volume corresponding to the star polymer with the indicated number of branches. This position was estimated from a universal calibration curve $^{32}$ of GPC, using a relation between the intrinsic viscosity $[\eta]$ and the number of branches for star molecule. ${ }^{28}$

As seen from Figure 1, the unfractionted polymer (LBW27) contains one- (linear), three- and fourbranched components, together with a small amount of two-branched (linear) component. After the fractionation, however, nearly all the linear molecules are considered to have been eliminated, though we cannot completely rule out the presence of a trace of two-branched component. From these results and the $P$ values in Table $I$, it can be concluded that the branched samples employed in this study are mixtures of three- and four-branched polystyrenes. $P$ for any one sample is around 3.5 , suggesting that these branched samples are mixtures of three- and four-branched polymers.

The dynamic viscoelasticities of $50 \mathrm{wt} \%$ solutions of all the samples and those of $90 \mathrm{wt} \%$ solutions of three samples were measured. Partially chlorinated biphenyl, Kaneclor 500 (KC5), was used as the solvent.

\section{Measurements of the Viscoelasticity}

Measurement of viscoelastic properties was carried out on a concentric cylinder-type rheometer described previously. $6,7,9,30,33$ The angular frequency $(\omega)$.was varied from $2.8 \times 10^{-2}$ to $3.5 \mathrm{~s}^{-1}$, and the temperature, from 40 to $280^{\circ} \mathrm{C}$.

The frequency dependence curves of the storage modulus $G^{\prime}(\omega)$ and the loss modulus $G^{\prime \prime}(\omega)$ at various temperatures were reduced to master curves according to the time-temperature superposition principle. The reference temperatures were $50^{\circ} \mathrm{C}$ for $50 \mathrm{wt} \%$ solutions and $120^{\circ} \mathrm{C}$ for $90 \mathrm{wt} \%$ solutions. In order to compare the viscoelastic properties of the concentrated solutions with those of the undiluted polymers, the master curves for various concentrations were shifted to an iso-free-volume state, ${ }^{33}$ in which the fractional free volume $(f)$ is equal to 0.0608 .

\section{RESULTS AND DISCUSSION}

\section{Frequency Dependence of Viscoelastic Functions}

The master curves for storage modulus $\left(G^{\prime}\right)$ and loss modulus $\left(G^{\prime \prime}\right)$ at $50^{\circ} \mathrm{C}$ for $50 \mathrm{wt} \%$ solutions of the star polymers are shown in Figures 2 and 3, respectively. As the molecular weight increases, the flow region shifts progressively to low frequency, and the rubbery plateau becomes wider. $G^{\prime \prime}$ curves, except that for LB29 show peaks in the rubber-flow transition region. Similar behavior was observed for $90 \mathrm{wt} \%$ solutions of the star polymers.

In Figures 4 and 5, the master curves of $G^{\prime}$ and

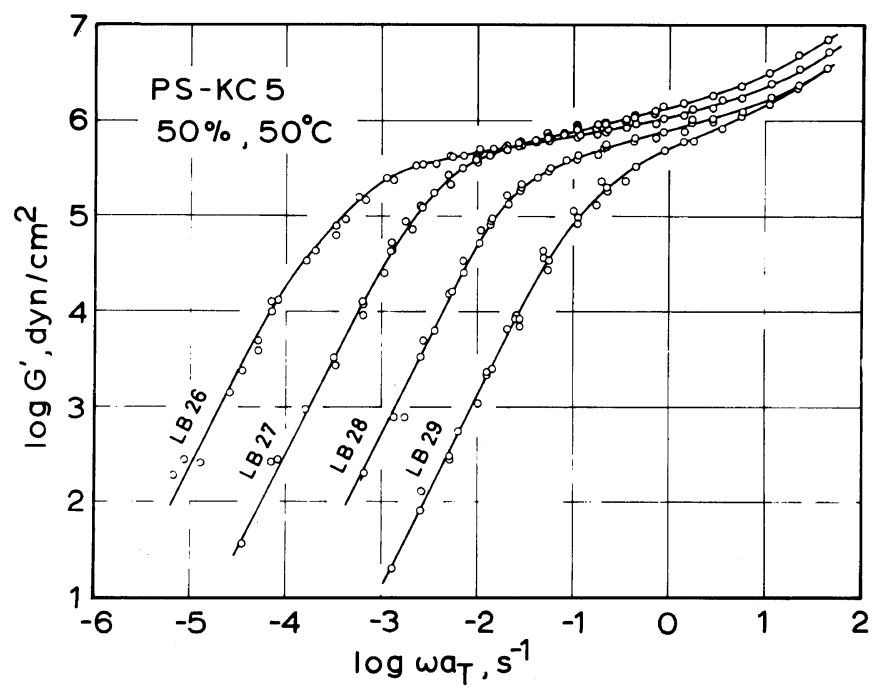

Figure 2. Master curves of $G^{\prime}$ for $50 \mathrm{wt} \%$ solutions of star-shaped polystyrenes in $\mathrm{KC} 5$. The reference temperature is $50^{\circ} \mathrm{C}$. 


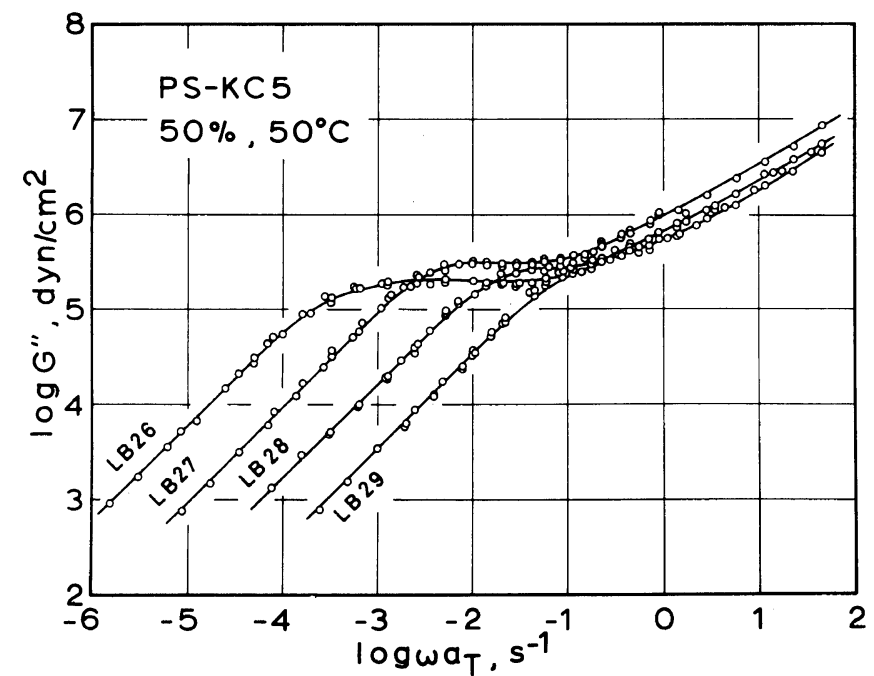

Figure 3. Master curves of $G^{\prime \prime}$ for $50 \mathrm{wt} \%$ solutions of star-shaped polystyrenes in KC5. The reference temperature is $50^{\circ} \mathrm{C}$.

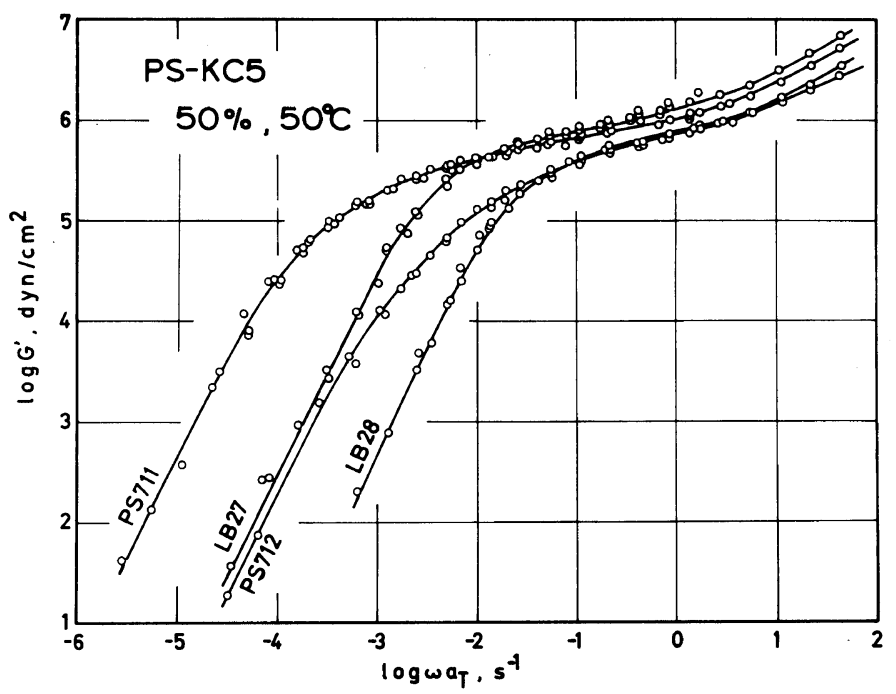

Figure 4. Comparison of $G^{\prime}$ curves for $50 \mathrm{wt} \%$ solutions of linear and star-shaped polystyrenes at $50^{\circ} \mathrm{C}$.

$G^{\prime \prime}$ for $50 \mathrm{wt} \%$ solutions of the star polystyrenes are compared with those for linear ones having about the same molecular weights and molecular weight distributions. Here, PS711 and PS712 correspond to LB27 and LB28, respectively, as seen from Table I. $G^{\prime}$ for the branched samples changes more sharply than that for linear samples at the frequencies between the rubbery and flow regions, corresponding to the fact that the $G^{\prime \prime}$ curves of star polymers show peaks in the rubber-to-flow tran- sition region. This suggests that the distribution of entanglement relaxation times for a star polymer is narrower than that of a linear polymer with the same molecular weight distribution. On the other hand, Graessley and Roovers ${ }^{20}$ recently found that the distribution of relaxation times associated with the entanglement relaxations was found to be narrower for linear polymers than for star polymers for monodisperse samples. The difference between their results and ours might be due to the following 


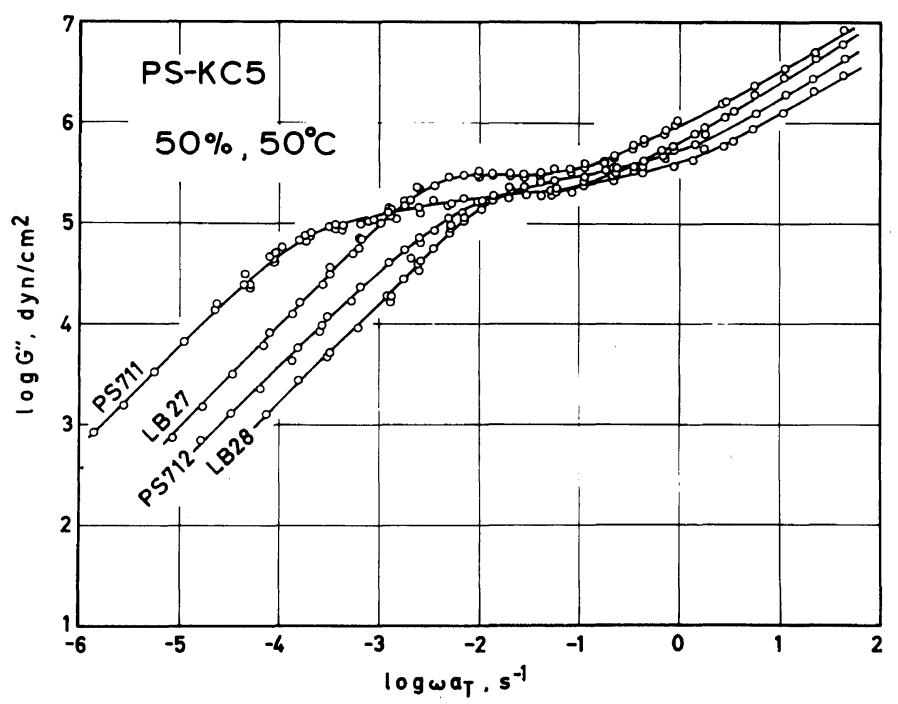

Figure 5. Comparison of $G^{\prime \prime}$ curves for $50 \mathrm{wt} \%$ solutions of linear and star-shaped polystyrenes at $50^{\circ} \mathrm{C}$.

reason: the average entanglement relaxation times for three- and four-branched star polymers are closer to each other than to those for linear polymers of the corresponding molecular weights, so that the distribution for the mixture of star polymers is apparently narrower than that for linear ones with the same molecular weight distribution.

\section{Zero-Shear Viscosity}

In Figure 6, the molecular weight $\left(M_{w}\right)$ dependence of the zero-shear viscosity $\eta_{0}$ in the isofree-volume state ${ }^{33}$ is shown for the star polymers, where $\eta_{0}$ is defined by

$$
\eta_{0}=\lim _{\omega \rightarrow 0} G^{\prime \prime}(\omega) / \omega
$$

In this figure, the open circles are the data for undiluted star-shaped polystyrenes ${ }^{16}$ and the rightblack and left-black circles are those for $90 \mathrm{wt} \%$ and $50 \mathrm{wt} \%$ solutions of the same samples, respectively. $\eta_{0}$ for solutions of high molecular weight polymers can be expressed by a straight line having a slope of 4.5 , which is the same as that for undiluted polymers. Similar results were reported not only for star-shaped polymers ${ }^{14,17-22}$ but also for combshaped polystyrenes with a fixed number of branches. ${ }^{11,12}$ In the same figure, the zero-shear viscosities for $90 \mathrm{wt} \%$ and $50 \mathrm{wt} \%$ solutions are

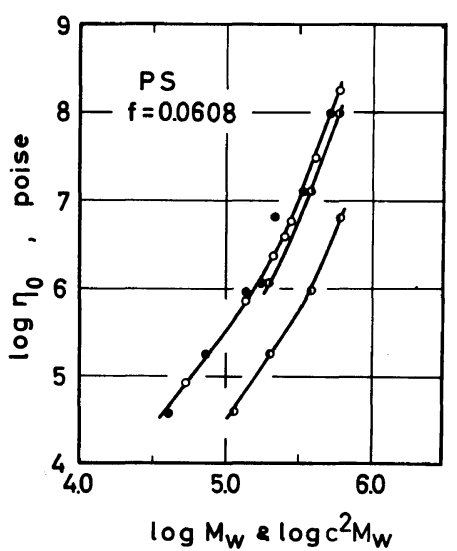

Figure 6. Molecular weight dependences of zero-shear viscosity $\eta_{0}$ for undiluted star-shaped polystyrenes and their solutions in an iso-free-volume state, $f=0.0608$. Open circles, right-black circles, and left-black circles indicate the data for undiluted polystyrenes, $90 \mathrm{wt} \%$ and $50 \mathrm{wt} \%$ solutions of star-shaped polystyrenes, respectively. Zero-shear viscosity $\eta_{0}$ at $f=0.0608$ logarithmically plotted against $c^{2} M_{w}$ are shown by closed circles.

plotted against $c^{2} M_{w}$ instead of $M_{w}$ with closed circles, where $c$ is the concentration in $\mathrm{g} \mathrm{ml}^{-1}$. The closed circles fall on the line for undiluted samples, suggesting that the effect of concentration on $\eta_{0}$ of star polystyrenes can be scaled by $c^{2}$ rather than by $c$. This result is different from that reported for linear polymers by Berry and Fox. ${ }^{34}$ 


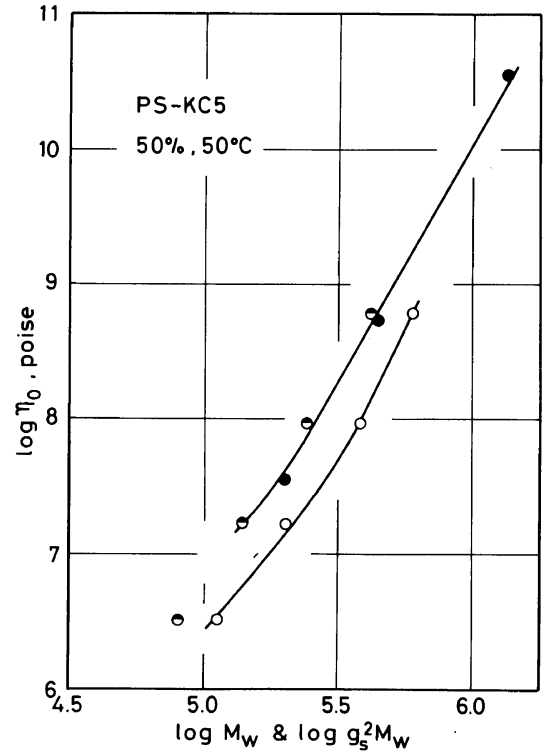

Figure 7. Zero-shear viscosity $\eta_{0}$ for $50 \mathrm{wt} \%$ solutions at $50^{\circ} \mathrm{C}$ logarithmically plotted against $M_{w}$ (open circles) and the corrected molecular weight $g_{\mathrm{s}}{ }^{2} M_{w}$ (top-black circles). Closed circles indicate the data for linear polystyrenes.

The molecular weight dependence of $\eta_{0}$ for $50 \mathrm{wt} \%$ solutions of the star polymers (open circles) and that of the linear polymers (closed circles) are shown in Figure 7. The star polymers show lower values of $\eta_{0}$ over the entire range of molecular weight covered in this study. $\eta_{0}$ for the linear polymers can be expressed by a straight line having a slope of 3.5, and that for the star polymers with higher molecular weights has a slope of 4.5 as mentioned before.

According to the idea ${ }^{35}$ that the viscosity of polymer liquids is determined by the dimension of polymer chain, the $\eta_{0}$ of branched polymers is often plotted against $g_{\mathrm{s}}{ }^{2} M_{w}$ instead of $M_{w}$ and compared with that of linear polymers. ${ }^{18,20,28} g_{\mathrm{s}}{ }^{2}$ is the ratio of mean-square radius of gyration $\left\langle s^{2}\right\rangle_{b}$ for a branched polymer to that for a linear polymer of the same molecular weight, and it is given by

$$
g_{\mathrm{s}}=\left\langle s^{2}\right\rangle_{\mathrm{b}} /\left\langle s^{2}\right\rangle_{1}=(3 P-2) / P^{2}
$$

for a regular star structure ${ }^{36}$ with a monodisperse length of branch and a monodisperse number of branches. For a monodisperse length of branch but an incomplete coupling with the distribution in the number of branches we have,

$$
g_{\mathrm{s}}^{2}=[1+3(f-1) \alpha] /[1+(f-1) \alpha]^{2}
$$

where $\alpha$ is the fraction of the actually utilized number of reactive groups $f$ of the coupling agent. ${ }^{37}$ In this study, we used the $g_{\mathrm{s}}^{2}$ values calculated from eq 2 using the average values of $P$ in Table $\mathrm{I}$, instead of those from eq 3 using $f=4$ and $\alpha=P / 4$, because these two equations give similar values for $g_{\mathrm{s}}{ }^{2}$. $\log$ $\eta_{0}$ is plotted against $\log g_{\mathrm{s}}^{2} M_{w}$ with the top-black circles in Figure 7. The plots for the star branched polymers coincide well with the $\log \eta_{0} v s . \log M_{w}$ curve for the linear polymers. The same results were reported for undiluted star-branched polybutadienes ${ }^{14}$ and for undiluted star-branched polystyrenes ${ }^{34}$ in the low molecular weight region where the viscosity of branched polymers does not exceed that of linear polymer. On the other hand, it was reported that the $\log \eta_{0} v s . \log g_{\mathrm{s}}{ }^{2} M_{w}$ relations for four- and six-branched polyisoprene solutions ${ }^{18}$ and for six-branched polystyrenes ${ }^{26}$ were a little lower than that for linear polymers and that a successful superposition could be attained by plotting $\log \eta_{0}$ against $\log g_{\mathrm{s}}^{2.4} M$ at low molcular weights. ${ }^{17,18}$ The slope of the $\log \eta_{0} v s . \log M_{w}$ curves for mixtures of star polymers of high molecular weights is 4.5 , as can be seen from Figure 6. This implies that $\eta_{0}$ for mixtures of star polymers should appear above that for linear polymers for $M_{w}>1.0 \times 10^{6}$.

\section{Steady-State Compliance}

Another important parameter determining the elastic properties in the flow region is the steadystate compliance defined by

$$
J_{\mathrm{e}}{ }^{0}=\lim _{\omega \rightarrow 0} \frac{G^{\prime}(\omega)}{G^{\prime 2}(\omega)+G^{\prime \prime 2}(\omega)}
$$

The molecular weight dependence of $J_{\mathrm{e}}^{0}$ for mixtures of star polymers is shown in Figure 8, where the left-black, right-black and black circles represent data for $50 \mathrm{wt} \%$ solutions, $90 \mathrm{wt} \%$ solutions and undiluted polymers, ${ }^{16}$ respectively. $J_{\mathrm{e}}{ }^{0}$ for undiluted monodisperse linear polystyrenes reported previously ${ }^{33}$ is also shown by a broken line, and the data obtained by Utracki et al. ${ }^{17}$ for four-branched polystyrenes in diethylbenzene at $c=25.5 \mathrm{~g} \mathrm{dl}^{-1}$ and $30^{\circ} \mathrm{C}$ are illustrated by the top-black circles in the same figure. As is evident from Figure 1, the master curves of the storage modulus $G^{\prime}$ for $50 \mathrm{wt} \%$ solutions of star polymers show the rubbery plateau. Therefore, the product of concentration and mo- 


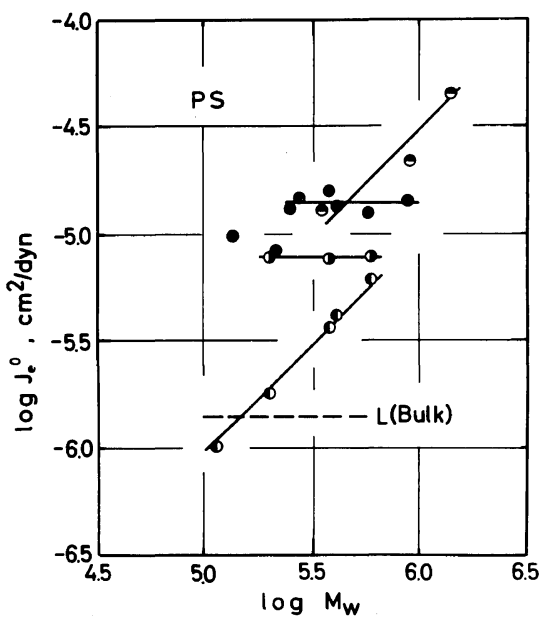

Figure 8. Molecular weight dependences of steadystate compliance $J_{\mathrm{e}}^{0}$ for undiluted star polymers (closed circles), and $90 \mathrm{wt} \%$ (right-black circles), and $50 \mathrm{wt} \%$ (left-black circles) solutions of star-shaped polystyrenes. The broken line indicates the results for undiluted linear polystyrene. The top-black circles represent the data for four-branched polystyrene in diethylbenzene $(c=0.255$ $\mathrm{g} \mathrm{ml}^{-1}$ ) at $30^{\circ} \mathrm{C}$ reported by Utracki et al. ${ }^{17}$

lecular weight $(c M)$ used in this study was high enough to bring all the solutions into the entanglement region.

It is surprising that $J_{\mathrm{e}}^{0}$ of the solutions are lower than those of undiluted polymers. Such behavior has not been observed for solutions of linear polymers. Moreover, $\mathrm{J}_{\mathrm{e}}{ }^{0}$ for $50 \mathrm{wt} \%$ solutions are even lower than those for $90 \mathrm{wt} \%$ solutions and undiluted polymers. From these results it follows that the $J_{\mathrm{e}}{ }^{0}$ for mixtures of three- and four-branched polystyrenes in the high concentration region decreases by dilution in contrast to the observations with linear polymers. A similar tendency has been observed for randomly branched polystyrenes ${ }^{9}$ and poly(vinyl acetate) $^{38}$ in moderately concentrated and concentrated solutions.

$J_{\mathrm{e}}{ }^{0}$ for $90 \mathrm{wt} \%$ solutions and undiluted polymers are independent of molecular weight and about ten times as high as that for linear polymers. A similar result was reported by Fujimoto et al., for combshaped polystyrenes. ${ }^{11,12}$ This behavior of mixtures of star polymers differs from that of four- ${ }^{19}$ and six-branched star polystyrenes ${ }^{20,26}$ having no distribution in the number of branches, for which $J_{\mathrm{e}}{ }^{0}$ is proportional to $M_{w}$. This difference may be attributed to the shape of distribution of relaxa-

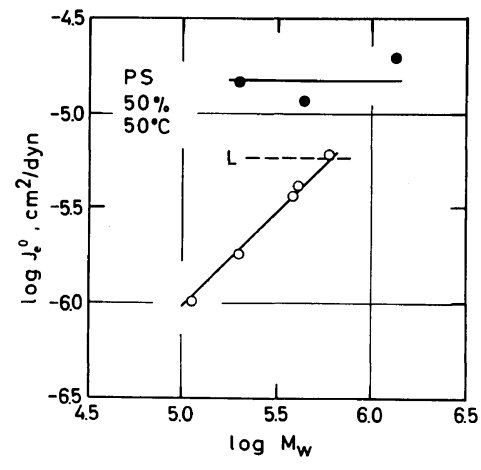

Figure 9. Molecular weight dependences of steadystate compliance $J_{\mathrm{e}}{ }^{0}$ for $50 \mathrm{wt} \%$ solutions of star-shaped (open circles) and linear polystyrenes of almost the same molecular weight distribution (closed circles). The broken line indicates the result for monodisperse linear polymer. ${ }^{27}$

tion times at long times in the mixture of star polymers with a different number of branches.

Another difference in $J_{\mathrm{e}}{ }^{0}$ for linear polymers and a mixture of branched polymers is found in its molecular weight dependence in the entanglement region. As is evident from Figure $8, J_{\mathrm{e}}{ }^{0}$ for $50 \mathrm{wt} \%$ solutions increases in proportion to the molecular weight. Similar behavior in $J_{\mathrm{e}}{ }^{0}$ for concentrated solutions has been found for randomly branched polystyrenes $^{9}$ and for star-branched polyisoprenes. ${ }^{18}$ The behavior of $J_{\mathrm{e}}{ }^{0}$ for mixtures of branched polymers is quite different from that of solutions of linear polymer, for which $J_{\mathrm{e}}{ }^{0}$ is independent of molecular weight and proportional to $c^{-2}$ in the region of molecular weight and concentration (entanglement region) ${ }^{39}$ where $G^{\prime}(\omega)$ curve has a rubbery plateau. $J_{\mathrm{e}}^{0}$ for $0.255 \mathrm{~g} \mathrm{~m}^{-1}$ solutions of four-branched polystyrenes reported by Utracki et al. ${ }^{17}$ is higher than that for $50 \mathrm{wt} \%(0.641$ $\mathrm{g} \mathrm{ml}^{-1}$ ) solution used in the present study as shown Figure 8 , where $J_{\mathrm{e}}{ }^{0}$ for both solutions are in proportion to $M_{w}$. The details of the concentration dependence of $J_{\mathrm{e}}{ }^{0}$ will be described in a subsequent paper of this series. ${ }^{40}$

The molecular weight dependence of $J_{\mathrm{e}}^{0}$ for $50 \mathrm{wt} \%$ solutions of star polystyrenes is compared with that of linear polystyrenes in Figure 9, where the open circles denote the star polymers and the filled circles the linear polymers. These two polymers have nearly the same molecular weight distribution, as is seen from Table I. The broken line represents $J_{\mathrm{e}}^{0}$ for monodisperse linear polymers. It 
is evident from this figure that $J_{\mathrm{e}}{ }^{0}$ for $50 \mathrm{wt} \%$ solutions of star polymers used in this study is lower than that of linear polymers, contrary to the case of undiluted polymers. ${ }^{16}$

As reported in several papers, ${ }^{18,20,26} J_{\mathrm{e}}{ }^{0}$ for star polymers having $P$ lower than six is proportional to $M_{w}$, and the plots of $\log J_{\mathrm{e}}^{0}$ against $\log g_{2} M_{w}$ fall well on the $\log J_{\mathrm{e}}{ }^{0} v s$. $\log M_{w}$ curve for linear polymers in the region of $g_{2} M_{w}$ lower than $M_{\mathrm{c}}{ }^{\prime}$. Here, $M_{\mathrm{c}}{ }^{\prime}$ is the critical molecular weight where the molecular weight dependence of $J_{\mathrm{e}}{ }^{0}$ of linear polymers changes from $M_{w}^{1.0}$ to $M_{w}{ }^{0}$ and $g_{2}$ is given by,

$$
g_{2}=(15 P-14) /(3 P-2)^{2}
$$

for star polymers having $P$ branches of equal length. ${ }^{25} g_{2}$ values is roughly equal to $(2 / P)$ values and so $g_{2}$ can be replaced by $2 / P$,

$$
g_{2} \simeq(2 / P)=2 M_{\mathrm{s}} / M
$$

where $M_{\mathrm{s}}$ is the molecular weight of one branch. The relation between the critical concentration and molecular weight for linear polymers is represented by, ${ }^{39}$

$$
M c_{\mathrm{c}}{ }^{\prime}=M_{\mathrm{c}}{ }^{\prime} c=\left(M_{\mathrm{c}}{ }^{\prime}\right)_{\mathrm{bulk}} \rho
$$

where $\left(M_{\mathrm{c}}{ }^{\prime}\right)_{\text {bulk }}$ and $\rho$ are the critical molecular weight and density for undiluted polymers, respectively. The value of $\left(M_{\mathrm{c}}{ }^{\prime}\right)_{\text {bulk }} \rho$ was estimated ${ }^{39}$ to be $1.3 \times 10^{5}$. If this relation can be extended to star polymers, $J_{\mathrm{e}}{ }^{0}$ for star polymers may show the same behavior in the entanglement region as that for linear polymers in the region of $g_{2} M_{w} \simeq$ $2 M_{\mathrm{s}}>M_{\mathrm{c}}{ }^{\prime}$. On the other hand, $J_{\mathrm{e}}{ }^{0}$ for star polymer shows the Rouse like behavior for $2 M_{\mathrm{s}}<$ $M_{\mathrm{c}}{ }^{\prime}$. Values of $M_{\mathrm{c}}{ }^{\prime} / 2$ for $90 \mathrm{wt} \%$ solutions and $50 \mathrm{wt} \%$ solutions of the star polymers are evaluated to be $6.7 \times 10^{4}$ and $1.0 \times 10^{5}$, respectively. These values may be compared with the molecular weight of one branch $M_{\mathrm{s}}$ for each sample shown in Table I.

As mentioned before, a successful superposition can be attained by plotting $\log J_{\mathrm{e}}{ }^{0}$ against $\log g_{2} M_{w}$ for star and linear polymers, and $g_{2} M_{w}$ is nearly equal to $2 M_{\mathrm{s}}$. Accordingly, $J_{\mathrm{e}}{ }^{0}$ of three- and fourbranched polymers having the same $M_{\mathrm{s}}$ are nearly equal to each other and also to those of linear polymers of $M=2 M_{\mathrm{s}}$ for $M_{\mathrm{s}}<M_{\mathrm{c}}{ }^{\prime} / 2 . J_{\mathrm{e}}^{0}$ for star polymers with $M_{\mathrm{s}}>M_{\mathrm{c}}{ }^{\prime} / 2$ become higher than those of linear polymers, because $J_{\mathrm{e}}^{0}$ of star polymers are proportional to $M$. For $50 \mathrm{wt} \%$ solutions of the star polymers used in this study, $2 M_{\mathrm{s}}$ is lower than $M_{\mathrm{c}}{ }^{\prime}$, so that $J_{\mathrm{e}}{ }^{0}$ for three- and four-branched star polystyrenes, the components of the mixture, are almost the same as that of $50 \mathrm{wt} \%$ solutions of linear polymers with $M=2 M_{\mathrm{s}} . J_{\mathrm{e}}{ }^{0}$ of mixture of linear polymers in the Rouse region is represented by, ${ }^{30}$

$$
J_{\mathrm{e}}{ }^{0}=\frac{2}{5} \frac{M_{w}}{c R T}\left(\frac{M_{z} M_{z+1}}{M_{w}{ }^{2}}\right)
$$

where $M_{z}$ and $M_{z+1}$ are $z$ - and $(z+1)$-average molecular weights, respectively. If $J_{\mathrm{e}}^{0}$ of a mixture of star polymers whose branches are equal in length but different in number can also be represented by eq 8 for $M_{\mathrm{s}}<M_{\mathrm{c}}{ }^{\prime} / 2, J_{\mathrm{e}}{ }^{0}$ will be proportional to $M_{w}$. This would be true for the $50 \mathrm{wt} \%$ solutions.

On the other hand, $J_{\mathrm{e}}{ }^{0}$ for $90 \mathrm{wt} \%$ solutions of the mixture are higher than those of linear polymer solutions of the same concentration, as seen from Figure 8 . The steady-state compliance of mixtures may be much higher due to the following effects of branching and blending: (1) $J_{\mathrm{e}}^{0}$ of star-shaped polystyrenes increase with molecular weight even for high molecular weights of branches, ${ }^{20,22}$ in contrast to linear correspondences, and gives mixtures high $J_{\mathrm{e}}{ }^{0}$ values. (2) $J_{\mathrm{e}}{ }^{0}$ of a binary blend ${ }^{31}$ of linear polymers can be expressed by.

$$
J_{\mathrm{e}}{ }^{0}=J_{\mathrm{e}_{2}}^{0}\left(\frac{M_{z}}{M_{w}}\right)^{3.7}
$$

where $J_{\mathrm{e}_{2}}^{0}$ is the steady-state compliance of the high molecular weight component in the blend. This effect causes $J_{\mathrm{e}}{ }^{0}$ of mixtures to become higher. The problems that still remains to be solved is concerned with the experimental fact that $J_{\mathrm{e}}{ }^{0}$ for branched

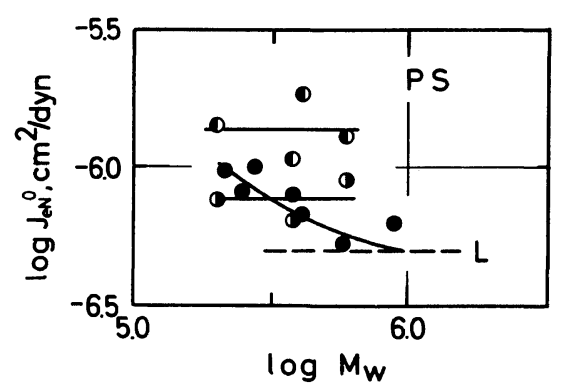

Figure 10. Molecular weight dependences of entanglement compliance $J_{\mathrm{eN}}^{0}$ for undiluted star polymers (closed circles), and $90 \mathrm{wt} \%$ (right-black circles) and $50 \mathrm{wt} \%$ (left-black circles) solutions of star-shaped polystyrenes. The broken line indicates the results for undiluted linear polystyrene. ${ }^{33}$ 
Rheological Properties of Anionic Polystyrenes. IX.

Table II. Numerical values of zero-shear viscosity $\eta_{0}$, steady-state compliance $J_{\mathrm{e}}^{0}$, and entanglement compliance $J_{\mathrm{eN}}^{0}$ at $50^{\circ} \mathrm{C}$ for $50 \mathrm{wt} \%$ solutions of star polystyrenes

\begin{tabular}{|c|c|c|c|c|}
\hline \multirow{2}{*}{ Sample } & \multirow{2}{*}{$M_{w} \times 10^{-5}$} & $\eta_{0}$ & \multirow{2}{*}{$\frac{J_{\mathrm{e}}^{0}}{\mathrm{~cm}^{2} \mathrm{dyn}^{-1}}$} & \multirow{2}{*}{$\frac{J_{\mathrm{eN}}^{0}}{\mathrm{~cm}^{2} \mathrm{dyn}^{-1}}$} \\
\hline & & poises & & \\
\hline LB26 & 5.95 & $6.1 \times 10^{8}$ & $6.2 \times 10^{-6}$ & $1.13 \times 10^{-6}$ \\
\hline LB27 & 3.80 & $9.2 \times 10^{7}$ & $3.7 \times 10^{-6}$ & $1.08 \times 10^{-6}$ \\
\hline LB28 & 2.00 & $1.66 \times 10^{7}$ & $1.8 \times 10^{-6}$ & $1.43 \times 10^{-6}$ \\
\hline LB29 & 1.13 & $3.55 \times 10^{6}$ & $1.03 \times 10^{-6}$ & - \\
\hline
\end{tabular}

Table III. Numerical values of zero-shear viscosity $\eta_{0}$, steady-state compliance $J_{\mathrm{e}}{ }^{0}$ and entanglement compliance $J_{\mathrm{eN}}^{0}$ at $120^{\circ} \mathrm{C}$ for

$90 \mathrm{wt} \%$ solutions of star polystyrenes

\begin{tabular}{|c|c|c|c|c|}
\hline \multirow{2}{*}{ Sample } & \multirow{2}{*}{$M_{w} \times 10^{-5}$} & $\eta_{0}$ & \multirow{2}{*}{$\frac{J_{\mathrm{e}}^{0}}{\mathrm{~cm}^{2} \mathrm{dyn}^{-1}}$} & \multirow{2}{*}{$\frac{J_{\mathrm{eN}}^{0}}{\mathrm{~cm}^{2} \mathrm{dyn}^{-1}}$} \\
\hline & & poises & & \\
\hline LB26 & 5.95 & $3.52 \times 10^{8}$ & $8.0 \times 10^{-6}$ & $9.24 \times 10^{-7}$ \\
\hline LB27 & 3.80 & $4.30 \times 10^{7}$ & $7.9 \times 10^{-6}$ & $6.55 \times 10^{-7}$ \\
\hline LB28 & 2.00 & $4.40 \times 10^{6}$ & $7.9 \times 10^{-6}$ & $7.72 \times 10^{-7}$ \\
\hline
\end{tabular}

polymers with a distribution in the number of branches is abnormally high at high concentrations.

\section{Entanglement Compliance}

An important parameter for characterizing the rubbery region of a polymer liquid is the entanglement modulus $G_{\mathrm{eN}}^{0}$ or the entanglement compliance $J_{\mathrm{eN}}^{0}=1 / G_{\mathrm{eN}}^{0}$. These parameters can be evaluated ${ }^{41}$ by numerical integration of the peak area of $G^{\prime \prime}(\omega)$.

The molecular weight dependence of $J_{\mathrm{eN}}^{0}$ evaluated for mixtures of star polymers is shown in Figure 10. The symbols used are the same as in Figure 8. As is evident from this figure, $J_{\mathrm{eN}}^{0}$ for undiluted polymers is somewhat higher than that of linear polymers at lower molecular weights, but it decreases gradually as the molecular weight increases to the value for linear polymers. ${ }^{16} J_{\mathrm{eN}}^{0}$ for 90 and $50 \mathrm{wt} \%$ solutions are independent of molecular weight, and $J_{\mathrm{eN}}^{0}$ for the latter is higher than that for the former, in marked contrast to the behavior of $J_{\mathrm{e}}{ }^{0}$. The numerical values of $\eta_{0}, J_{\mathrm{e}}{ }^{0}$ and $J_{\mathrm{eN}}^{0}$ at $50^{\circ} \mathrm{C}$ obtained in this work are tabulated in Table II for $50 \mathrm{wt} \%$ solutions of star polymers. The corresponding values at $120^{\circ} \mathrm{C}$ for $90 \mathrm{wt} \%$ solutions of star polymers are given in Table III.
Acknowledgement. This work was supported in part by a Grant-in-Aid for Scientific Research from the Ministry of Education, Science and Culture of Japan (No. 443021). We wish to thank Dr. T. Hayashi of our department for his assistance in the ultracentrifugal analysis.

\section{REFERENCES}

1. A. Charlesby, J. Polym. Sci., 17, 379 (1955).

2. L. D. Moore, Jr., J. Polym. Sci., 36, 155 (1959).

3. L. H. Tung, J. Polym. Sci., 46, 409 (1960).

4. W. L. Peticolas, J. Polym. Sci., 58, 1405 (1962).

5. V. C. Long, G. C. Berry, and L. M. Hobbs, Polymer, 5, 517 (1964).

6. S. Onogi, S. Kimura, T. Kato, T. Masuda, and N. Miyanaga, J. Polym. Sci., C15, 381 (1966).

7. S. Onogi, T. Masuda, and T. Ibaragi, Kolloid Z. Z Polym., 222, 110 (1968).

8. W. W. Graessley and J. S. Prentice, J. Polym. Sci., A-2, 6, 1887 (1968).

9. T. Masuda, Y. Nakagawa, Y. Ohta, and S. Onogi, Polym. J., 3, 92 (1972).

10. E. M. Valles and C. W. Macosko, Macromolecules, 12, 521 (1979).

11. T. Fujimoto, H. Narukawa, and M. Nagasawa, Macromolecules, 3, 57 (1970).

12. T. Fujimoto, H. Kajiura, M. Hirose, and M. 


\section{Y. Ohta, M. Kitamura, T. Masuda, and S. OnOgi}

Nagasawa, Polym. J., 3, 181 (1972).

13. J. Pannell, Polymer, 13, 2 (1972).

14. G. Kraus and J. T. Gruver, J. Polym. Sci., A, 3, 105 (1965); $A-2,8,305$ (1970).

15. D. P. Wyman, L. J. Elyash, and W. J. Frazer, J. Polym. Sci., A, 3, 681 (1965).

16. T. Masuda, Y. Ohta, and S. Onogi, Macromolecules, 4, 763 (1971).

17. L. A. Utracki and J. E. L. Roovers, Macromolecules, 6, 366; 373 (1973).

18. W. W. Graessley, T. Masuda, J. E. L. Roovers, and N. Hadjichristidis, Macromolecules, 9, 127 (1976).

19. H. Kajiura, Y. Ushiyama, Y. Fujimoto, and M. Nagasawa, Macromolecules, 11, 894 (1978).

20. W. W. Graessley and J. Roovers, Macromolecules, 12, 959 (1979).

21. V. R. Raju, H. Rachapudy, and W. W. Graessley, J. Polym. Sci., Polym. Phys. Ed., 17, 1223 (1979).

22. Y. Isono, T. Fujimoto, H. Inagaki, M. Shishido, and M. Nagasawa, Polym. J., 12, 131 (1980).

23. Y. Isono, T. Fujimoto, $H$. Kajiura, and $M$. Nagasawa, Polym. J., 12, 369 (1980).

24. P. E. Rouse, J. Chem. Phys., 21, 1272 (1953).

25. J. S. Ham, J. Chem. Phys., 26, 625 (1957).

26. T. Masuda, Y. Ohta, M. Kitamura, Y. Saito, K. Kato, and S. Onogi, Macromolecules, 14, in press.
27. Y. Ohta, Y. Saito, Y. Masuda, and S. Onogi, Macromolecules, submitted.

28. S. Bywater, Adv. Polym. Sci., 30, 89 (1979).

29. A. L. Soli and J. L. Shrag, Macromolecules, 12, 1159 (1979).

30. T. Masuda, K. Kitagawa, T. Inoue, and S. Onogi, Macromolecules, 3, 116 (1970).

31. T. Masuda, M. Takahashi, and S. Onogi, Appl. Polym. Symp., 20, 49 (1973).

32. Z. Grubisic, P. Rempp, and H. Benoit, J. Polym. Sci., B, 5, 753 (1967).

33. S. Onogi, T. Masuda, and K. Kitagawa, Macromolecules, 3, 109 (1970).

34. G. C. Berry and T. G. Fox, Adv. Polym. Sci., 5, 261 (1968).

35. F. Bueche, J. Chem. Phys., 40, 484 (1964).

36. B. H. Zimm and W. H. Stockmayer, J. Chem. Phys., 17, 1301 (1949)

37. W. Burchard, Macromolecules, 7, 841 (1974).

38. W. W. Graessley and E. S. Shinbach, J. Polym. Sci., Polym. Phys. Ed., 12, 2047 (1974).

39. W. W. Graessley, Adv. Polym. Sci., 16, 1 (1974).

40. T. Masuda, Y. Ohta, M. Kitamura, M. Minamide, K. Kato, and S. Onogi, Polym. J., 13, 869 (1981).

41. J. D. Ferry, "Viscoelastic Properties of Polymers," 3rd ed., Wiley, New York, 1980, Chapter 13. 